Research Article

\title{
Herbal products: a survey of students' perception and knowledge about their medicinal use
}

\author{
Kavita Sekhri $^{\mathrm{a}}{ }^{*}$, Sangeeta Bhanwra ${ }^{\mathrm{b}}$, Ruchika Nandha ${ }^{\mathrm{a}}$
}

\author{
${ }^{\mathrm{a} D e p a r t m e n t}$ of Pharmacology, \\ Dr. Harvansh Singh Judge \\ Institute of Dental Sciences, \\ Panjab University, Chandigarh, \\ India \\ ${ }^{\mathrm{b}}$ Department of Pharmacology, \\ Govt. Medical College and \\ Hospital, Sector 32, Chandigarh, \\ India
}

Received: 13 December 2012 Accepted: 21 December 2012

\author{
*Correspondence to: \\ Dr. Kavita Sekhri, \\ Email: \\ message2kavita@yahoo.com
}

\begin{abstract}
Background: As herbal therapies are increasingly being used around the world because they are perceived to be free of side effects, it is important that prescribers should be made aware of their possible harm or herb-drug interactions. In this context present study was undertaken among dental students to assess their knowledge and attitude towards the use of herbal products as medicines.

Methods: A detailed questionnaire having both open and close-ended questions to assess students' perception, awareness and usage of herbal medication was given to 90 second year students in a teaching dental hospital. Data was expressed as counts and percentages.

Results: A total response rate of $93.3 \%$ was observed. $60.77 \%$ of respondents had used herbal medication for various ailments. Highest frequency of the use was recorded for ginger $(37.5 \%)$ followed by neem $(16.66 \%)$, turmeric $(15 \%)$ and tulsi $(13.33 \%)$. Elders at home $(86 \%)$ was cited the most common source of herbal product information. Students were familiar with the use of clove, aloe vera, turmeric and neem but St. John's wort and Gingko biloba are ones that were generally not known to them. $67.64 \%$ indicated unawareness about safety concerns and herb-drug interactions. Most (68.65\%) agreed that they did not tell their physician about taking herbal products. $58.73 \%$ preferred herbal products over allopathic medicine.

Conclusions: There is a need to impart knowledge to the students about the usage of herbal products as these are frequently used to treat various health problems. Students should be sensitized about their safety concerns and potential drug interactions.
\end{abstract}

Keywords: Herbal products, Knowledge, Herb-drug interaction

\section{INTRODUCTION}

Products made from botanicals that are used to maintain or improve health may be called herbal products or herbal medicines. ${ }^{1}$ They come under the class of complementary and alternative medicine (CAM). Herbal medicines have been used for thousands of years in developing countries and more than $80 \%$ of the population relies on their use for health care needs. ${ }^{2}$ High prevalence of obesity, chronic disorders, pain syndromes, and anxiety or desire for good health collectively lead to their increased use in the present world. ${ }^{3}$ These alternative therapies are quickly gaining importance as they are perceived to be free of side effects, considering their natural origin. ${ }^{4}$ But actually herbal remedies are complex mixtures of organic chemicals and have many adverse effects owing to their active ingredients or interactions with conventional drugs that can sometimes produce life threatening consequences. ${ }^{5}$

Although some medical schools around the world offer education in complementary medicine, but the actual proportion of medical schools imparting education on herbal medicines, remains low. ${ }^{6}$ So, in order to provide insight into the use of herbal remedies and examine issues surrounding their use, a study was undertaken amongst the students of second professional Bachelor in Dental Surgery (B.D.S) course to assess the awareness about available herbal products and the prevalence of their medicinal usage.

\section{METHODS}


The study was conducted among dental students of second year in the department of pharmacology of a dental college in Northern India. A detailed questionnaire consisting of 12 questions with 2-4 options was given to each of the students. The questionnaire was based on previous studies undertaken on students or adults about their attitude regarding herbal medicines and their consumption and it was suitably modified for the present setting. ${ }^{7,8}$ It was a free will questionnaire (Appendix 1) which was validated by a pilot study done on 20 students. Students were asked to tick the option whichever they felt was most appropriate without revealing their identity in the questionnaire. The completed questionnaires were collected and analyzed for the data. Data was expressed as counts and percentages.

\section{RESULTS}

Out of the 90 students who were given questionnaires, 84 students completed and returned the questionnaires, giving a response rate of $93.3 \%$. Mean age of the students was $19.6 \pm 0.87$ years. Out of a total of 90 students, 76 were females. It was observed that some of the students did not attempt few questions or ticked multiple options. $52.22 \%$ of the students admitted that they were fully aware of the fact that herbal products could be used as medicine whereas $46.26 \%$ had little knowledge about it. $60.77 \%$ of respondents had used herbal medication in the past for various ailments. Herbal products most frequently used by students are depicted in figure 1 .

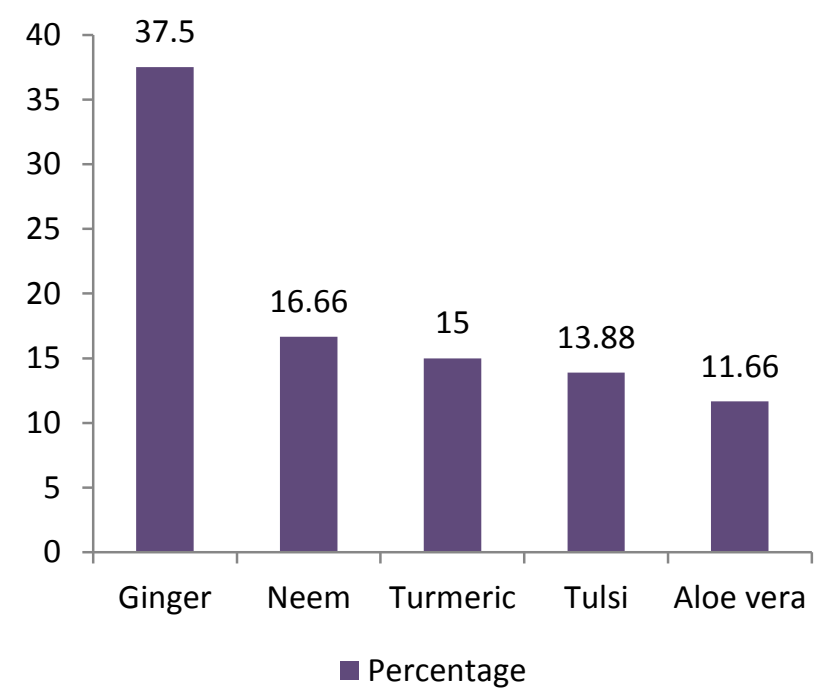

Figure 1: Herbal products most frequently used by students.

Majority $(85.1 \%)$ of the respondents found the treatment to be effective. Only two out of ninety students reported side effects with the use of herbal remedies. The side effect reported were skin rash and stinging with the use of neem tablets.
The commonest sources of herbal product information were elders at home (86\%), followed by media (9\%) and friends' advice (5\%). Students were familiar with the uses of Garlic, Cinnamon, Clove, Aloe Vera, Turmeric and Neem but St John's wort and Gingko biloba were the ones that were generally not known to them (Table 1).

Table 1: Students' familiarity with the use of different herbal products.

\begin{tabular}{|l|l|}
\hline Herbal Product & $\begin{array}{l}\% \text { of students familiar } \\
\text { with it }\end{array}$ \\
\hline Turmeric & $71.1 \%$ \\
\hline Neem & $71.1 \%$ \\
\hline Aloe Vera & $70 \%$ \\
\hline Garlic & $65.5 \%$ \\
\hline Clove & $62.2 \%$ \\
\hline Cinnamon & $53.3 \%$ \\
\hline Gingko biloba & $18.8 \%$ \\
\hline Saint John Wort & nil \\
\hline
\end{tabular}

Most common ailment treated with the use of these herbal remedies was found to be cough and cold (40\%), followed in decreasing order by acne $(29 \%)$, throat infections $(11 \%)$, wound healing $(8 \%)$, toothache $(6 \%)$ and other conditions like bee sting and memory enhancement (6\%). Most respondents (68.65\%) agreed that they did not inform their physician about taking herbal products along with the medicines prescribed by them, giving various reasons (Table 2). A total of $67.64 \%$ students indicated their unawareness about the safety concerns associated with the use of herbal products and herb-drug interactions. $58.73 \%$ preferred herbal products over allopathic medicine. Majority (82.5\%) preferred herbal products because they considered Herbal products as natural and safe with no side effects (Table 3). Whopping $95.45 \%$ of students expressed their desire to know more about these products.

\section{Table 2: Reasons for not informing the physician of herbal drug usage.}

\begin{tabular}{|ll|}
\hline Reasons & Percentage of respondents \\
\hline Viewing them as irrelevant & 25.5 \\
\hline Of no interest to physician & 21.27 \\
\hline $\begin{array}{l}\text { Such remedies are not } \\
\text { related to physician's field } \\
\text { of expertise }\end{array}$ & 42.55 \\
\hline Doctor did not ask & 10.6 \\
\hline
\end{tabular}


Table 3: Summary of reasons for preference of herbal products.

\begin{tabular}{|ll|}
\hline Reasons & Percentage of respondents \\
\hline $\begin{array}{l}\text { Natural with no side } \\
\text { effects }\end{array}$ & 82.5 \\
\hline $\begin{array}{l}\text { Promote general well- } \\
\text { being }\end{array}$ & 10 \\
\hline Family tradition & 5 \\
\hline Others (More efficacious) & 2.5 \\
\hline
\end{tabular}

\section{DISCUSSION}

This survey highlights the familiarity of students with herbal products and their use as an alternative to the conventional medicine. The prevalence of herb drug usage in the present study is found to be similar to the previous studies which have reported $26-79 \%$ usage for herb and dietary supplementation among college and university students. ${ }^{9-11}$ Most common ailment associated with the use of herbal remedies was found to be cough and cold which was also reported by Gardiner et al who mentioned cough \& cold, stomach or intestinal conditions as the most common ones for herb use among young adults in United States (US). ${ }^{12}$

Consistent with a study in 1000 university students in US, the present study found family to be a major source of information and recommendation concerning herbal product use. ${ }^{13}$ Similarly, Kara, and Rivera et al reported from studies in the Turkey and USA respectively that people generally follow the trusted advice of family members and friends. ${ }^{14,15}$ Reliance on the family advice about herbal use indicates a general lack of scientific attitude among users. Herbal remedies are as old as humankind but their traditional use is not a good indicator of its efficacy. There are many herbal medicines whose efficacy is established by placebo controlled randomized controlled trials. ${ }^{16}$ Only those medications which have a sufficient scientific evidence to support their use should be relied upon, instead of blindly following friend or family advice.

Informing their doctors about the simultaneous herbal medicine use was uncommon among the respondents and the reasons cited for non-disclosure mirrors some of the reasons mentioned in the previous studies. ${ }^{17,18}$ In another study conducted on young adult patients in US, only $24 \%$ disclosed the use of herbal products to their health care professional. ${ }^{11}$ Similarly, poor communication between patients and health care professionals regarding herbal product use was also reported by other studies. ${ }^{14,19,20}$ Respondents using herbal medicines without informing the treating physician may have to bear the brunt of serious clinical implications due to the possible herb-drug interactions. It has been found that herbal products interact or interfere with the normal pharmacology of some drugs with potentially fatal consequences. ${ }^{21}$ Ginkgo biloba, for example has been associated with bleeding, especially when combined with conventional antithrombotics or anticoagulants. ${ }^{22}$ Similarly garlic and ginkgo biloba both have an antiplatelet constituent and hence should be used with caution with other antiplatelet drugs. ${ }^{23}$ Cases reporting spinal hemorrhage caused by combined use of ginkgo biloba and high dose of acetaminophen are documented in literature. ${ }^{24}$ St John's wort has become the most documented herbal product which is involved in drug interactions. ${ }^{25}$ This gives a clear message that all the physicians should routinely include questions related to the use of herbal medicines into their history taking, so as to avoid potentially serious consequences. Rather it is imperative that both physicians and consumers should be aware of the side effects and possibility of potential herb-drug interactions.

The side effects reported with the use of neem tablets emphasize the fact that herbal products are complex mixture of organic and inorganic chemicals, which are further modified during extraction, compounding and packaging for the market use, thereby drifting them away from their original traditional milieu. This might cause a negative impact on the patients' health. ${ }^{4}$

Until now there were no regulations or legal standards that apply to harvesting, processing or packaging of herbal products. But recently in 2011, initiative was taken up in this direction in United Kingdom where Medicines and Healthcare products regulatory agency (MHRA) was set up. It is now mandatory for all herbal remedies to be registered with MHRA. Product packaging of these herbal remedies will display a traditional herbal registration (THR) certification mark which will establish their required standards for safety, quality and evidence of traditional use. This will help in minimizing the use of potential harmful products among users. ${ }^{26}$

Majority of the participants preferring herbal medicine over allopathic medicine indicated their belief on the efficacy and safety of herbal products reflecting a positive attitude towards using these medications. At the same time quoting "Herbs are natural with no side effects" reflected their lack of knowledge and exposure to herbal medicines in their formal education. Keeping in view the sharp upward trend in the acceptance of herbal substances as part of mainstream health milieu, the need of the hour is to increase awareness and knowledge about safety, potential harmful effects, herb-drug interaction and rational use of such medicines. ${ }^{27}$

This can be achieved by organizing continuing medical education programs or incorporating relevant topics in herbal medicine in pharmacology curriculum, as majority of the students in this study also expressed their will to know more about these drugs. This will go a long way in ensuring rational use of herbal products among students and preparing future clinicians who can address such issues in their patients responsibly. 


\section{CONCLUSION}

It is evident from the present study that the students' awareness of potential harmful effects and interaction between herbal medicine and conventional medicine is lacking. So it needs to be emphasized that given the widespread use of these products students should be equipped with appropriate knowledge in order to keep them away from possible harms and at the same time preparing them for providing optimal care and counseling for their future patients.

Funding: No funding sources

Competing interests: None declared

Ethical approval: Not required

\section{APPENDIX-1}

\section{Questionnaire}

Title: Awareness about available herbal products and their medicinal usage amongst the second professional dental students.

Age/Sex -

1. Are you aware that natural products can be used as medicines?
a) No knowledge
b) Little knowledge
c) Fully aware

2. Have you ever used herbal product as medicine?

Yes/No

2a. If yes name the herbal product and the condition in which it is used.

Name

Condition for which used-

3. Was the treatment
a) Effective
b) Ineffective

4. What was the source of information regarding the product?

a) Elders at home

b) Media (newspaper/internet/TV)

c) Friend advice

5. Any side effect observed-

$\mathrm{Yes} / \mathrm{No}$

If yes mention- 
6. Are you familiar with the name of following products?

$$
\text { Yes or No Condition in which it is used }
$$

\section{St. John Wort}

Garlic

Cinnamon

Gingko biloba

Clove

Aloe vera

Turmeric

Neem

7. Do you discuss taking these medications with your physician?

Yes/No

8. If not reason of not discussing about these-

a) Viewing them as irrelevant

b) Of no interest to physician

c) Such remedies are not related to physician's field of expertise

d) Doctor did not ask

9. Preference of treatment-

a) Herbal products or traditional medicine

b) Allopathic medicine

10. If preference is Herbal products, mark reasons-

a) They are natural with no side effect

b) They promote general well being

c) Family tradition

d) Any other reason?

11. Are you aware of safety concerns with herbal medicines or possible interactions with allopathic drugs? Yes/No

12. Do you wish to know more about these herbal products?

Yes/No 


\section{REFERENCES}

1. National Institutes of Health Office of Dietary Supplements. Botanical Dietary Supplements: Background Information. Available at http://ods.od.nih.gov/factsheets/botanicalbackground. asp. Accessed 12 December 2012.

2. Duraz AY, Khan SA. Knowledge, attitudes and awareness of community pharmacists towards the use of herbal medicines in muscat region. Oman Med J 2011;26:451-3.

3. Tachjian A, Maria V, Jahangir A. Use of herbal products and potential interactions in patients with cardiovascular diseases. J Am Coll Cardiol 2010;55:515-25.

4. Walker PS, Donovan JA. Herbal remedies: natural caveats. Int J Dermatol 1999;38:746-8.

5. Bent S. Herbal medicine in the United States: review of efficacy, safety, and regulation: grand rounds at University of California, San Francisco Medical Center. J Gen Intern Med 2008;23:854-9.

6. Mikail CN, Hearney E, Nemesure B. Increasing physician awareness of the common uses and contraindications of herbal medicines: utility of a case-based tutorial for residents. J Altern Complement Med 2003;9:571-6.

7. Zimmerman C, Kandiah J. A pilot study to assess students' perceptions, familiarity, and knowledge in the use of complementary and alternative herbal supplements in health promotion. Altern Ther Health Med 2012;18:28-33.

8. Gardiner P, Graham R, Legedza AT, Ahn AC, Eisenberg DM, Phillips RS. Factors associated with herbal therapy use by adults in the United States. Altern Ther Health Med 2007;13:22-9.

9. Ambrose ET, Samuels S. Perception and use of herbals among students and their practitioners in a university setting. J Am Acad Nurse Pract 2004; 16:166-73.

10. Johnson SK, Blanchard A. Alternative medicine and herbal use among university students. J Am Coll Health 2006;55:163-8.

11. Newberry H, Beerman K, Duncan S, McGuire M, Hillers V. Use of nonvitamin, nonmineral dietary supplements among college students. J Am Coll Health 2001;50:123-9.

12. Gardiner P, Kemper KJ, Legedza A, Phillips RS. Factors associated with herb and dietary supplement use by young adults in the United States. BMC Complement Altern Med 2007;7:39.

13. Perkin JE, Wilson WJ, Schuster K, Rodriguez J, Allen-Chabot A. Prevalence of nonvitamin, nonmineral supplement usage among university students. J Am Diet Assoc 2002;102:412-4.

14. Kara B. Herbal product use in a sample of Turkish patients undergoing haemodialysis. J Clin Nurs 2009; 18:2197-205.

15. Rivera JO, Gonzalez-Stuart A, Ortiz M, Rodriguez JC, Anaya JP, Meza A. Herbal product use in nonHIV and HIV-positive Hispanic patients. J Natl Med Assoc 2005;97:1686-91.

16. Little JW. Complementary and alternative medicine: impact on dentistry. Oral Surg Oral Med Oral Pathol Oral Radiol Endod 2004;98:137-45.

17. Vickers KA, Jolly KB, Greenfield SM. Herbal medicine: women's views, knowledge and interaction with doctors: a qualitative study. BMC Complement Altern Med 2006;6:40.

18. Robison A, McGrail MR. Disclosure of CAM use to medical practitioners: a review of qualitative and quantitative studies. Complement Ther Med 2004;12:90-8.

19. Crawford NW, Cincotta DR, Lim A, Powell CV. A cross-sectional survey of complementary and alternative medicine use by children and adolescents attending the University Hospital of Wales. BMC Complement Altern Med 2006;6:16.

20. Nur N. Knowledge and behaviours related to herbal remedies: a cross-sectional epidemiological study in adults in Middle Anatolia, Turkey. Health Soc Care Community 2010;18:389-95.

21. Barnes PM, Powell-Griner E, McFann K, Nahin RL. Complementary and alternative medicine use among adults: United States, 2002. Adv Data 2004;(343):119.

22. De Smet PA. Herbal remedies. N Engl J Med 2002;347:2046-56.

23. Abebe W, Herman W, Konzelman J. Herbal supplement use among adult dental patients in a USA dental school clinic: prevalence, patient demographics, and clinical implications. Oral Surg Oral Med Oral Pathol Oral Radiol Endod 2011;111:320-5.

24. Abebe W. Herbal medication: potential for adverse interactions with analgesic drugs. J Clin Pharm Ther 2002;27:391-401.

25. Tirona RG, Bailey DG. Herbal product-drug interactions mediated by induction. $\mathrm{Br} \mathrm{J}$ Clin Pharmacol 2006;61:677-81.

26. Blakemore S. New herbal remedy safeguards. Primary Health Care 2011;21:6-7.

27. Kelly JP, Kaufman DW, Kelley K, Rosenberg L, Anderson TE, Mitchell AA. Recent trends in use of herbal and other natural products. Arch Intern Med 2005;165:281-6.

doi: 10.5455/2319-2003.ijbcp20130114

Cite this article as: Sekhri K, Bhanwra S, Nandha R. Herbal products: a survey of students' perception and knowledge about their medicinal use. Int J Basic Clin Pharmacol 2013;2:71-6. 